\title{
Mechanical Properties of Fiber Reinforced Lightweight Concrete Containing Surfactant
}

\author{
Yoo-Jae Kim, Jiong Hu, Soon-Jae Lee, and Byung-Hee You \\ Department of Engineering Technology, Texas State University, San Marcos, TX 78666, USA \\ Correspondence should be addressed to Yoo-Jae Kim, yk10@txstate.edu
}

Received 21 June 2010; Accepted 24 November 2010

Academic Editor: Tarun Kant

Copyright () 2010 Yoo-Jae Kim et al. This is an open access article distributed under the Creative Commons Attribution License, which permits unrestricted use, distribution, and reproduction in any medium, provided the original work is properly cited.

Fiber reinforced aerated lightweight concrete (FALC) was developed to reduce concrete's density and to improve its fire resistance, thermal conductivity, and energy absorption. Compression tests were performed to determine basic properties of FALC. The primary independent variables were the types and volume fraction of fibers, and the amount of air in the concrete. Polypropylene and carbon fibers were investigated at $0,1,2,3$, and $4 \%$ volume ratios. The lightweight aggregate used was made of expanded clay. A self-compaction agent was used to reduce the water-cement ratio and keep good workability. A surfactant was also added to introduce air into the concrete. This study provides basic information regarding the mechanical properties of FALC and compares FALC with fiber reinforced lightweight concrete. The properties investigated include the unit weight, uniaxial compressive strength, modulus of elasticity, and toughness index. Based on the properties, a stress-strain prediction model was proposed. It was demonstrated that the proposed model accurately predicts the stress-strain behavior of FALC.

\section{Introduction}

In the last three decades, prefabrication has been applied to small housing and tall building construction, and precast concrete panels have become one of the widely used materials in construction system. Recently, much attention has been directed toward the use of lightweight concrete for precast concrete to improve the performances, such as dead load reduction, fire resistance, and thermal conductivity, of the buildings. Additionally, the structure of a precast building should be able to resist impact loading cases, particularly earthquakes, since resisting earthquakes of these buildings under the performances is becoming an important consideration $[1,2]$.

Many efforts have been applied toward developing high performance concrete for building structures with enhanced performance and safety. Various types of precast concrete products, such as autoclaved aerated lightweight concrete (AALC), fiber reinforced concrete (FRC), and lightweight concrete, have been developed and experimentally verified. A number of them have been applied in full-scale building structures. AALC is well known and widely accepted, but its small size and weak strength limit its use in structural elements [3]. Lightweight aggregate concretes offer strength, dead load reduction, and thermal conductivity, but their limited ability to absorb earthquake energy raises concerns. In contrast, FRC has greater energy-absorbing ability, which is called "ductility or inelastic deformation capacity," than normal concrete, but its weight poses problems. Fiber aerated lightweight concrete (FALC) has a promising future for precast concrete panels that can be used in both small and tall building structures because it combines the comfort of AALC, the adaptability of lightweight aggregate concrete, and the reliability of FRC [4-6].

The purpose of this study is to investigate the material properties of FALC, including the compressive strength, modulus of elasticity and toughness index, with different densities, fibers, and volume fractions of fiber. Also, a new modulus of elasticity equation is presented, and the effects of fibers on strength and toughness are evaluated. Based on these properties, a stress-strain prediction model is proposed. 
TABle 1: Properties of fibers.

\begin{tabular}{lcccc}
\hline Types & $\begin{array}{c}\text { Modulus of } \\
\text { elasticity }(\mathrm{GPa})\end{array}$ & $\begin{array}{c}\text { Length } \\
(\mathrm{in})\end{array}$ & $\begin{array}{c}\text { Diam- } \\
\text { eter } \\
(\mathrm{in})\end{array}$ & $\begin{array}{c}\text { Reinforcing index } \\
\left(\mathrm{RI}=V_{f} \cdot l / \phi\right)\end{array}$ \\
\hline $\begin{array}{l}\text { Polypropylene } \\
\text { Carbon }\end{array}$ & 4.3 & 2.0 & 0.011 & $\mathrm{~V}_{f} \cdot 181$ \\
\hline
\end{tabular}

\section{Experimental Programs}

To perform this experiment, lightweight concrete mix designs with various densities, air volume, chopped fiber volume and types were used. To improve compressive strength and ductility, as well as the performances for wall panel, expanded clay coarse, fine aggregate, and surfactant to control the density, two different kinds of chopped fibers and self-compaction admixture were used for laboratory experiment. Also, preliminary test results included not only a complete stress-strain curve, but also a measure of ductility, such as energy to failure per unit strength, or ratio of failure strain to yield strain to find constitutive model. In this work, the surfactant contents were 0 and $0.1 \%$, and the fiber volume fractions were $0,1,2,3$, and $4 \%$.

2.1. Materials. The materials used consisted of early high strength Type I cement satisfying ASTM C150, coarse lightweight aggregate, and fine lightweight aggregate. A self-compaction agent (Sika ViscoCrete 6000) was used to reduce water and maintain good workability. Surfactant was used to control the density of concrete. Fibers currently being used in concrete can broadly be classified into two types. Low modulus, high elongation fibers, such as nylon, polypropylene, and polyethylene, are capable of large energy absorption characteristics. They do not improve strength; however, they impart toughness and resistance to impact and explosive loading. On the other hand, high strength, high modulus fibers such as steel, glass, asbestos, and carbon produce strong composites. They impart strength and stiffness to the composite and, to varying degrees, dynamic properties. Polypropylene and carbon fiber were used in this test. Table 1 presents the properties of these fibers. Tables 2 and 3 show properties of aggregates and admixtures, respectively.

2.2. Mixture Proportions. All the mixtures had a cement content of $560 \mathrm{~kg} / \mathrm{m}^{3}$ and a fiber content of $5.6,11.2,16.8$, or $22.4 \mathrm{~kg} / \mathrm{m}^{3}$. This cement content was chosen from the previous tests to provide a compressive strength of about $38 \mathrm{MPa}$. The water cement ratio was fixed at 0.45 . The selfcompaction agent provided maximum water reduction ( $10 \% \sim 45 \%$ of ordinary water cement ratio), increased early strength, and provided excellent plasticity while maintaining slump for up to two hours. To prevent tangling or balling of the fibers with consequent nonuniform fiber distribution, the self-compaction agent and a low shear mixer were used. Table 4 presents detailed mixing proportions.

Except for batches without surfactant, the same mixing procedure was followed for all batches. First, fine aggregate
TABle 2: Properties of aggregates.

\begin{tabular}{lccc}
\hline Type of aggregate & $\begin{array}{c}\text { Specific gravity } \\
(\text { SSD })\end{array}$ & $\begin{array}{c}\text { Specific gravity } \\
(\mathrm{OD})\end{array}$ & $\begin{array}{c}\text { Absorption } \\
(\%)\end{array}$ \\
\hline $\begin{array}{l}\text { Coarse expanded } \\
\text { clay }\end{array}$ & 1.30 & 1.06 & 22.3 \\
$\begin{array}{l}\text { Fine expanded } \\
\text { clay }\end{array}$ & 2.18 & 1.87 & 16.8 \\
\hline
\end{tabular}

TABle 3: Properties of admixtures.

\begin{tabular}{lcccc}
\hline Type & Type & Color & $\mathrm{pH}$ & $\begin{array}{c}\text { Specific } \\
\text { gravity }\end{array}$ \\
\hline $\begin{array}{l}\text { Self-compaction } \\
\text { agent (S.P) }\end{array}$ & Polycarboxylate & $\begin{array}{c}\text { Clear } \\
\text { amber }\end{array}$ & $5.5-7.5$ & 1.10 \\
Surfactant (S-1) & Polymer & White & $5.0-7.0$ & 1.04 \\
\hline
\end{tabular}

and water were mixed for 2 minutes to allow for absorption, since the fine lightweight aggregates were not presoaked. Then, cement was added with surfactant for 5 minutes to make air bubbles. Following that, coarse aggregate, fibers, and a self-compacting agent were mixed for 3 minutes. No tangling or balling of the fibers was observed during the mixing. Occasionally, the mixing time was longer than as described due to surfactant contingency.

2.3. Test Specimens. All the fiber aerated lightweight concrete cylinders for compression testing were $100 \times 200 \mathrm{~mm}$. The specimens were cast in plastic molds and were compacted by hand and vibrator. After casting, the specimens were covered with wet towels for 24 hours. They were then cured in a saturated water bath maintained at $23 \pm 2{ }^{\circ} \mathrm{C}$ for seven days. After four days of drying in the laboratory environment at 21 $\pm 2{ }^{\circ} \mathrm{C}$ and $50 \pm 15 \%$ humidity, they were tested.

All the specimens were tested in uniaxial compression using rigid steel plates on an MTS 100 ton test frame. Load and displacements were measured using the load cell and LVDT of the load frame. Axial strain was measured using extensometers located on opposite sides of the cylinder. The average of these extensometer readings was taken as the axial strain value. All the measurements were stored in the computer which runs the MTS test frame.

\section{Test Results}

3.1. Compressive Strength. According to the test results (Tables 5 and 6) for polypropylene fiber lightweight concrete with no surfactant, axial stresses ranged from 31.5 to 38.3 $\mathrm{MPa}$, with axial strain at peak stress varying from 0.0034 to $0.0044 \mathrm{~mm} / \mathrm{mm}$. For carbon fiber lightweight concrete with no surfactant, axial stresses ranged from 29.9 to $39.4 \mathrm{MPa}$, with axial strain at peak stress varying from 0.0037 to $0.0046 \mathrm{~mm} / \mathrm{mm}$.

Transversely, when $0.1 \%$ surfactant was used with polypropylene fiber lightweight concrete, axial stresses ranged from 12.1 to $17.0 \mathrm{MPa}$, with axial strain at peak stress varying from 0.0021 to $0.0028 \mathrm{~mm} / \mathrm{mm}$. For carbon fiber lightweight concrete with $0.1 \%$ surfactant, axial stresses 
TABLE 4: Mixing proportions.

\begin{tabular}{|c|c|c|c|c|c|c|c|c|c|c|c|c|}
\hline \multirow{2}{*}{$\begin{array}{l}\mathrm{W} / \mathrm{C} \\
(\%)\end{array}$} & \multirow{2}{*}{$\begin{array}{l}\mathrm{F} / \mathrm{A} \\
(\%)\end{array}$} & \multirow{2}{*}{$\begin{array}{l}\text { S.P } \\
(\%)\end{array}$} & \multirow{2}{*}{$\begin{array}{l}\text { S-1 } \\
(\%)\end{array}$} & \multirow[t]{2}{*}{ Types of fiber } & \multirow[t]{2}{*}{$\begin{array}{c}\text { Fiber }\left(\mathrm{V}_{f}\right) \\
(\%)\end{array}$} & \multicolumn{7}{|c|}{ Unit weight $\left(\mathrm{kg} / \mathrm{m}^{3}\right)$} \\
\hline & & & & & & Cement & Water & C.A & F.A & S.P & S-1 & Fiber \\
\hline \multirow{10}{*}{45} & \multirow{10}{*}{10} & \multirow{10}{*}{0.04} & \multirow{5}{*}{0} & \multirow{5}{*}{$\begin{array}{l}\text { Polypropylene } \\
\text { and carbon }\end{array}$} & 0 & \multirow{10}{*}{560} & \multirow{10}{*}{252} & \multirow{10}{*}{620} & \multirow{10}{*}{116} & \multirow{10}{*}{0.23} & \multirow{5}{*}{0} & 0 \\
\hline & & & & & 1 & & & & & & & 5.6 \\
\hline & & & & & 2 & & & & & & & 11.2 \\
\hline & & & & & 3 & & & & & & & 16.8 \\
\hline & & & & & 4 & & & & & & & 22.4 \\
\hline & & & \multirow{5}{*}{0.1} & \multirow{5}{*}{$\begin{array}{l}\text { Polypropylene } \\
\text { and carbon }\end{array}$} & 0 & & & & & & \multirow{5}{*}{0.56} & 0 \\
\hline & & & & & 1 & & & & & & & 5.6 \\
\hline & & & & & 2 & & & & & & & 11.2 \\
\hline & & & & & 3 & & & & & & & 16.8 \\
\hline & & & & & 4 & & & & & & & 22.4 \\
\hline
\end{tabular}

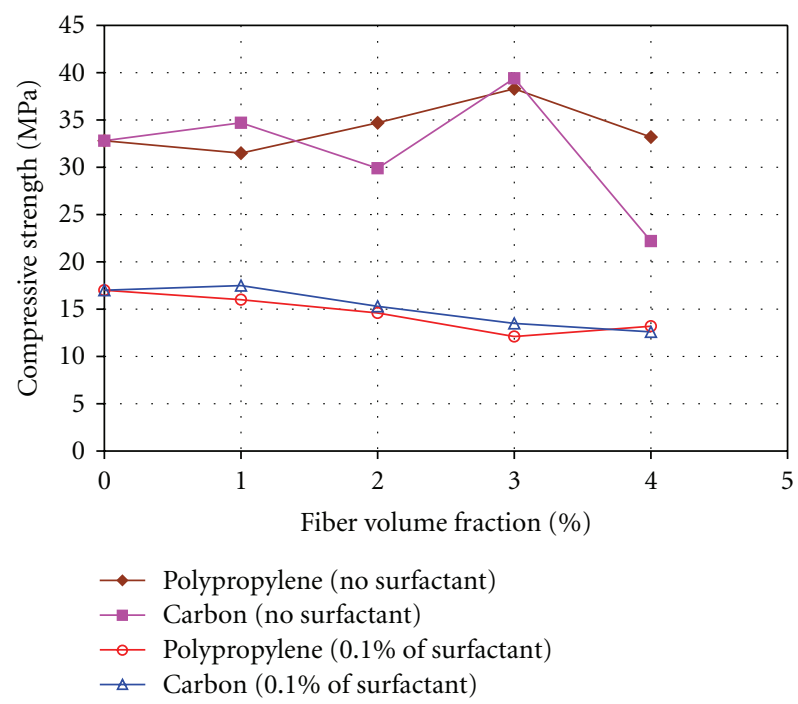

FIGURE 1: Fiber volume fraction versus compressive strength.

ranged from 12.6 to $17.5 \mathrm{MPa}$, with axial strain at peak stress varying from 0.0023 to $0.0031 \mathrm{~mm} / \mathrm{mm}$.

As shown in Table 6, when $0.1 \%$ of surfactant was added, compressive strength decreased by $50 \sim 58 \%$. In polypropylene and carbon fiber lightweight concrete with no surfactant, the addition of fibers further increased the strength up to $3 \%$ of fiber volume fraction. In both polypropylene and carbon fiber lightweight concrete with $0.1 \%$ surfactant, the increase of fiber resulted in gradual decrease of compressive strength. Thus, two main factors that decrease the compressive strength are observed to be fiber volume fraction and the amount of surfactant (Figure 1).

3.2. Modulus of Elasticity. Modulus of elasticity is a primary concern in concrete strength. In the case of fiber lightweight concrete without surfactant, the increase in the modulus of elasticity appears to be affected slightly by fiber volume fraction. Moreover, the decrease in the modulus of elasticity

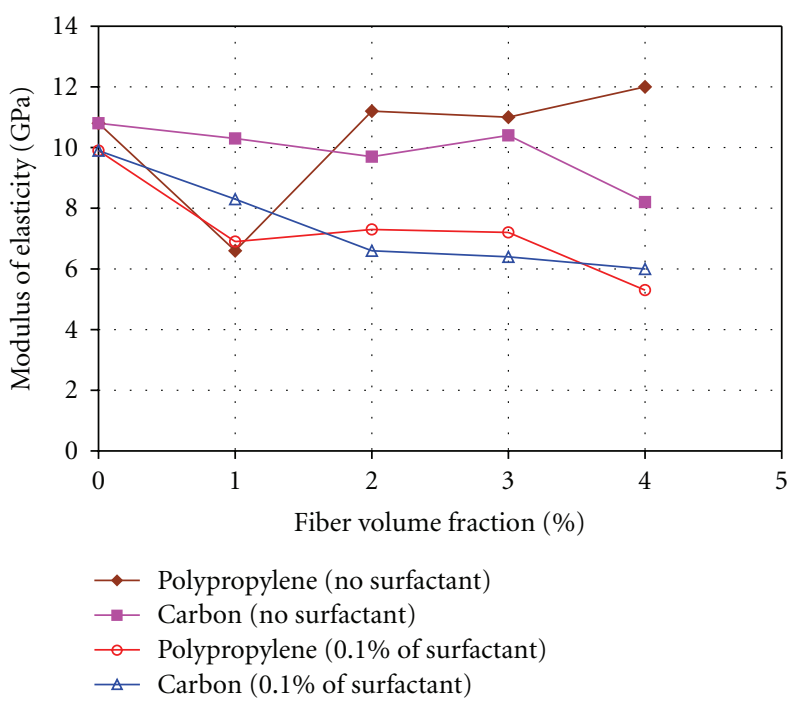

FIGURE 2: Fiber volume fraction versus modulus of elasticity.

provided by fibers with $0.1 \%$ surfactant was significant. For polypropylene and carbon fiber lightweight concrete with no surfactant, the modulus of elasticity ranged from 6.6 to $12.0 \mathrm{GPa}$, and 8.2 to $10.4 \mathrm{GPa}$, respectively. On the other hand, for polypropylene and carbon fiber lightweight concrete with $0.1 \%$ surfactant, the modulus of elasticity ranged from 5.3 to $7.3 \mathrm{GPa}$, and 6.0 to $8.3 \mathrm{GPa}$, respectively (see Table 5 and 6). According to Figure 2, the best fiber volume fraction for modulus of elasticity is between $2 \%$ and $3 \%$ in all cases.

According to ACI 318-05 [1], the modulus of elasticity of concrete depends on its compressive strength and density. However, there is not a specific equation for modulus of elasticity with unit weights between 1120 and $1440 \mathrm{~kg} / \mathrm{m}^{3}$. Figures 3 and 4 show the comparison of the modulus of elasticity of ACI equation with experimental data from both polypropylene fiber and carbon fiber. Comparison of the modulus of elasticity from experimental data to ACI 31805 equation shows that in unit weight between 1425.6 and 
TABLE 5: Properties of fiber lightweight concrete (no surfactant).

\begin{tabular}{|c|c|c|c|c|c|c|}
\hline Fiber & $\begin{array}{c}\text { Fiber } \\
\text { volume (\%) }\end{array}$ & $\begin{array}{l}\text { Unit weight } \\
\left(\mathrm{kg} / \mathrm{m}^{3}\right)\end{array}$ & $\begin{array}{c}\text { Compressive } \\
\text { strength }(\mathrm{MPa}) \\
\end{array}$ & $\begin{array}{c}\text { Axial strain } \\
\text { at peak }(\mathrm{mm} / \mathrm{mm})\end{array}$ & $\begin{array}{c}\text { Modulus of } \\
\text { elasticity }(\mathrm{GPa})\end{array}$ & $\begin{array}{c}\text { Toughness } \\
\text { index }\end{array}$ \\
\hline \multirow{5}{*}{ Polypropylene } & 0 & 1473.7 & 32.8 & 0.0037 & 10.8 & 1 \\
\hline & 1 & 1457.7 & 31.5 & 0.0044 & 6.6 & 1.03 \\
\hline & 2 & 1489.7 & 34.7 & 0.0044 & 11.2 & 1.26 \\
\hline & 3 & 1473.7 & 38.3 & 0.0040 & 11.0 & 1.29 \\
\hline & 4 & 1473.7 & 33.2 & 0.0034 & 12.0 & 1.33 \\
\hline \multirow{5}{*}{ Carbon } & 0 & 1473.7 & 32.8 & 0.0037 & 10.8 & 1 \\
\hline & 1 & 1425.6 & 34.7 & 0.0039 & 10.3 & 1.05 \\
\hline & 2 & 1141.7 & 29.9 & 0.0043 & 9.7 & 1.38 \\
\hline & 3 & 1505.7 & 39.4 & 0.0046 & 10.4 & 1.22 \\
\hline & 4 & 1457.7 & 22.2 & 0.0043 & 8.2 & 1.74 \\
\hline
\end{tabular}

TABLE 6: Properties of fiber aerated lightweight concrete $(0.1 \%$ surfactant $)$.

\begin{tabular}{|c|c|c|c|c|c|c|}
\hline Fiber & $\begin{array}{c}\text { Fiber } \\
\text { volume(\%) }\end{array}$ & $\begin{array}{l}\text { Unit weight } \\
\left(\mathrm{kg} / \mathrm{m}^{3}\right)\end{array}$ & $\begin{array}{c}\text { Compressive } \\
\text { strength }(\mathrm{MPa})\end{array}$ & $\begin{array}{c}\text { Axial strain } \\
\text { at peak }(\mathrm{mm} / \mathrm{mm})\end{array}$ & $\begin{array}{c}\text { Modulus of } \\
\text { elasticity }(\mathrm{GPa})\end{array}$ & $\begin{array}{c}\text { Toughness } \\
\text { index }\end{array}$ \\
\hline \multirow{5}{*}{ Polypropylene } & 0 & 1297.4 & 17.0 & 0.0023 & 9.9 & 1 \\
\hline & 1 & 1201.4 & 16.0 & 0.0028 & 6.9 & 2.11 \\
\hline & 2 & 1217.4 & 14.6 & 0.0023 & 7.3 & 2.22 \\
\hline & 3 & 1217.4 & 12.1 & 0.0021 & 7.2 & 2.58 \\
\hline & 4 & 1217.4 & 13.2 & 0.0029 & 5.3 & 2.75 \\
\hline \multirow{5}{*}{ Carbon } & 0 & 1297.5 & 17.0 & 0.0023 & 9.9 & 1 \\
\hline & 1 & 1249.4 & 17.5 & 0.0026 & 8.3 & 1.97 \\
\hline & 2 & 1201.4 & 15.3 & 0.0030 & 6.6 & 2.50 \\
\hline & 3 & 1137.3 & 13.5 & 0.0031 & 6.4 & 2.74 \\
\hline & 4 & 1217.4 & 12.6 & 0.0026 & 6.0 & 2.65 \\
\hline
\end{tabular}

$1489.7 \mathrm{~kg} / \mathrm{m}^{3}$ with both fibers, ACI 318-05 equation overestimates about 16 104\% of experimental data. Comparatively, in unit weight between 1137.3 and $1297.5 \mathrm{~kg} / \mathrm{m}^{3}$, the values of the modulus of elasticity with ACI Code 8.5 equation ranges from $-21 \%$ to $19 \%$ with both fibers. The influences of fiber volume fraction and unit weight on the modulus of elasticity are presented in Tables 5 and 6. Equation (1) relates these results to values calculated by means of the modulus of elasticity given in ACI 318-05

$$
E_{f c}=1.259192\left(1-e^{-0.8134 E_{c}}\right)\left(r^{2}=0.94\right),
$$

where $E_{f c}=$ modulus of elasticity of fiber aerated lightweight concrete, and $E_{c}=$ modulus of elasticity calculated by ACI 318-05 equation $(\mathrm{GPa})$.

3.3. Unit Weight. The unit weight of the concrete was measured at 7 days curing, and again after 4 days of drying in the laboratory environment at $21 \pm 2{ }^{\circ} \mathrm{C}$ and $50 \pm 15 \%$ humidity. The results are presented in Tables 5 and 6 . The unit weight of polypropylene fiber reinforced lightweight concrete ranged from 1467.7 to $1489.7 \mathrm{~kg} / \mathrm{m}^{3}$, with compressive strengths from 31.5 to $38.3 \mathrm{MPa}$. For carbon fiber reinforced lightweight concrete, unit weight varied from 1425.6 to $1505.7 \mathrm{~kg} / \mathrm{m}^{3}$, and compressive strengths varied from 29.9 to $39.4 \mathrm{MPa}$. For polypropylene fiber reinforced lightweight concrete with $0.1 \%$ surfactant and unit weights varying from 1201.4 to $1297.5 \mathrm{~kg} / \mathrm{m}^{3}$, compressive strengths ranged from 12.1 to $17.0 \mathrm{MPa}$. For carbon fiber reinforced lightweight concrete with $0.1 \%$ surfactant and unit weights varying from 1137.3 to $1297.5 \mathrm{~kg} / \mathrm{m}^{3}$, compressive strengths ranged from 12.6 to $17.5 \mathrm{MPa}$. It was found that there is no trend with respect to either fiber volume fraction or types of fiber.

3.4. Toughness Index (TI). One of the main objectives of adding fibers to a concrete matrix is to increase its toughness, its energy-absorbing capability, and make it more suitable for use in structures subjected to impact and earthquake loads. The normalized stress-strain curves (Figure 5) show that the slope of the ascending portion of the curves in fiber reinforced lightweight concrete is the same as for normal lightweight concrete. However, in the post-peak portion of the stress-strain curve, the curves gradually drop, then increase in strain capacity. Figure 6 indicates that the addition of fibers improved ductility to a limited extent. The increase of toughness with fiber volume fraction is more significant for carbon fiber than for polypropylene fiber [7].

The toughness index is defined here as the area under the stress-strain curve of fiber concrete up to a strain of 0.015 , divided by the area of no fiber lightweight concrete with 


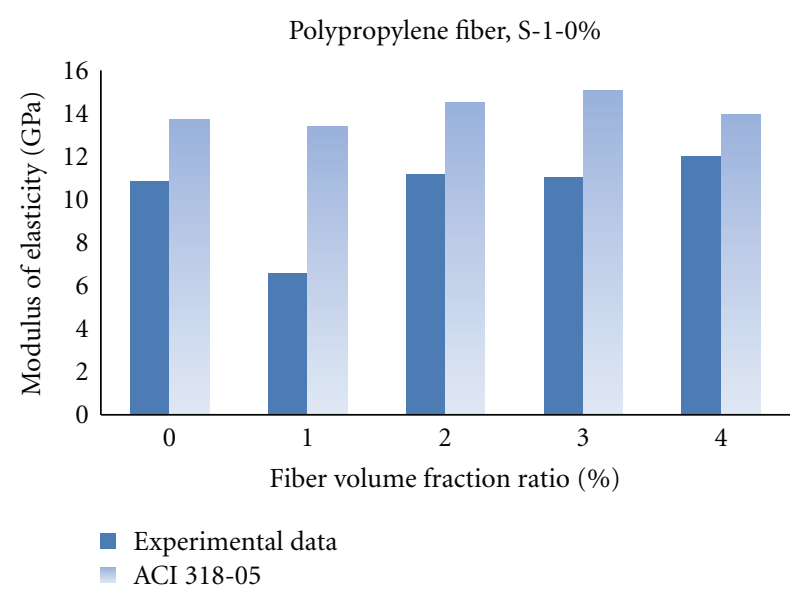

(a)

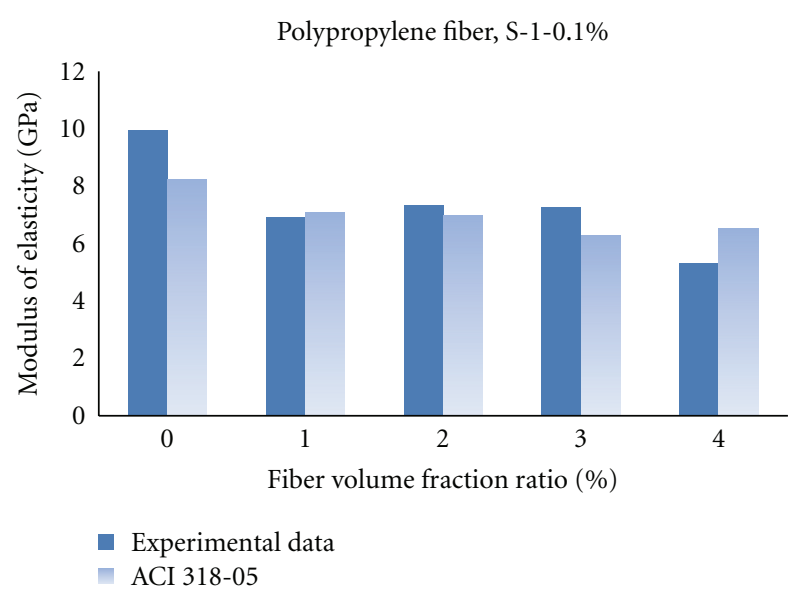

(b)

FIGURE 3: Comparison of modulus of elasticity of ACI code with experimental data (polypropylene fiber).

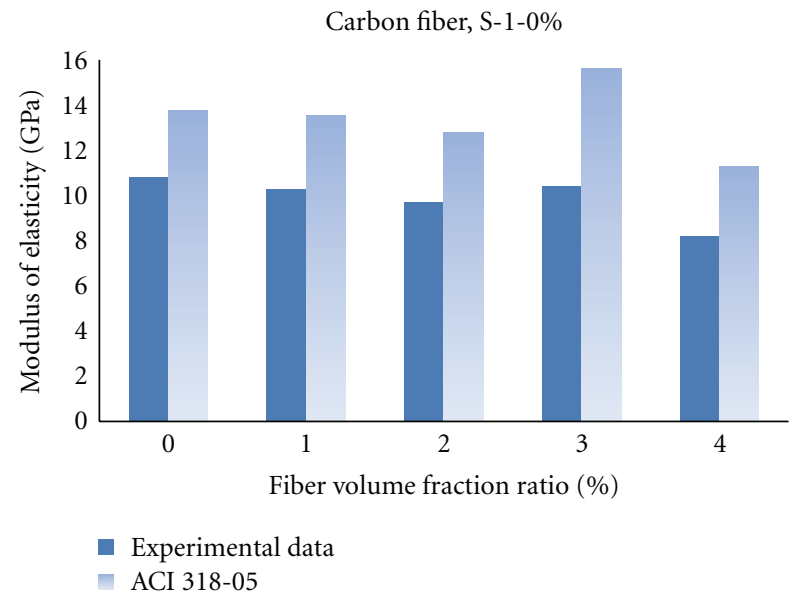

(a)

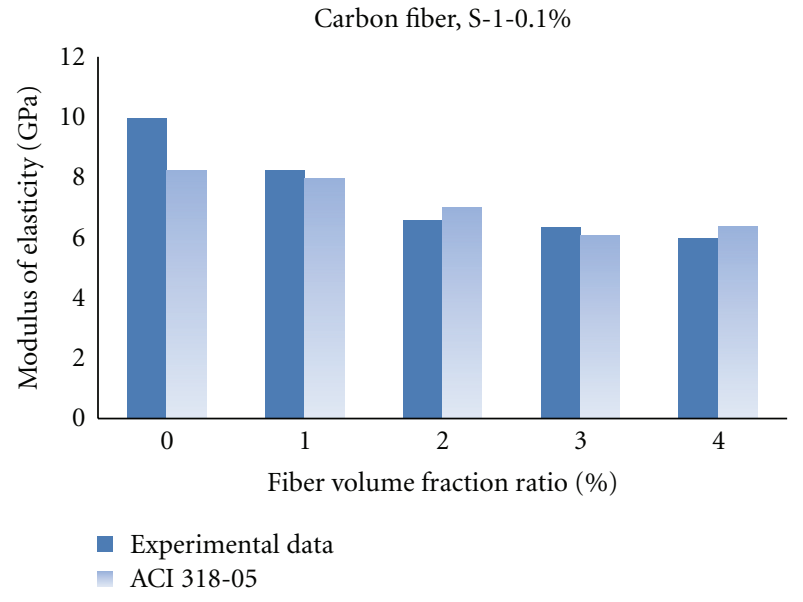

(b)

FIgURE 4: Comparison of modulus of elasticity of ACI code with experimental data (carbon fiber).

normalized stress up to a strain of 0.015 . The toughness of polypropylene and carbon fiber reinforced lightweight concrete with no surfactant ranged from 1.05 to 1.33 , and from 1.05 to 1.74 , respectively. However, with $0.1 \%$ surfactant, toughness ranged from 2.11 to 2.75 for polypropylene, and from 1.97 to 2.64 for carbon fiber

$$
\begin{gathered}
\mathrm{TI}=1.338+0.221 \cdot \mathrm{RI}\left(r^{2}=0.92\right) \text { for polypropylene fiber, } \\
\mathrm{TI}=1.354+0.023 \cdot \mathrm{RI}\left(r^{2}=0.89\right) \text { for carbon fiber, }
\end{gathered}
$$

where $\mathrm{RI}$ is the reinforcing index $\left(\mathrm{V}_{\mathrm{f}} \cdot l / \phi\right)$.

An increase in the volume fraction and modulus of elasticity of fibers generally led to a decrease in the slope of the descending portion of the stress-strain curve. For both fibers, an increase in fiber volume fraction led to similar results. The aspect ratio $(l / \phi)$ and the fiber volume fraction seemed to play an important role in improving the peak strain and the toughness of the composite. Improvements of the toughness index due to adding more fiber were relatively significant in lower unit weight concretes.

As mentioned above, the post-peak portion of the stressstrain curve for FALC is significantly related to the fiber aspect ratio and volume fraction. Therefore, an inflection point $\left(\varepsilon_{i}\right)$ based on the reinforcing index is selected for the descending portion of the curve for FALC. In the proposed equation by Ezeldin and Balaguru [4], the equation is derived from the inflection point modulus of elasticity from reinforcing index for high strength reinforced concrete, however, as indicated, the postpeak portion of stress-strain curve was different between high strength and lightweight concrete. In FALC, inflection point modulus of elasticity must be derived from modulus of elasticity of each fiber other than reinforcing index, then pick an inflection point based on toughness index is selected.

The following equation was derived:

$$
\mathcal{E}_{i}=\left(-0.009+1.74 \cdot \mathrm{TI}-0.467 \cdot \mathrm{TI}^{2}\right) \varepsilon_{0}\left(r^{2}=0.98\right)
$$




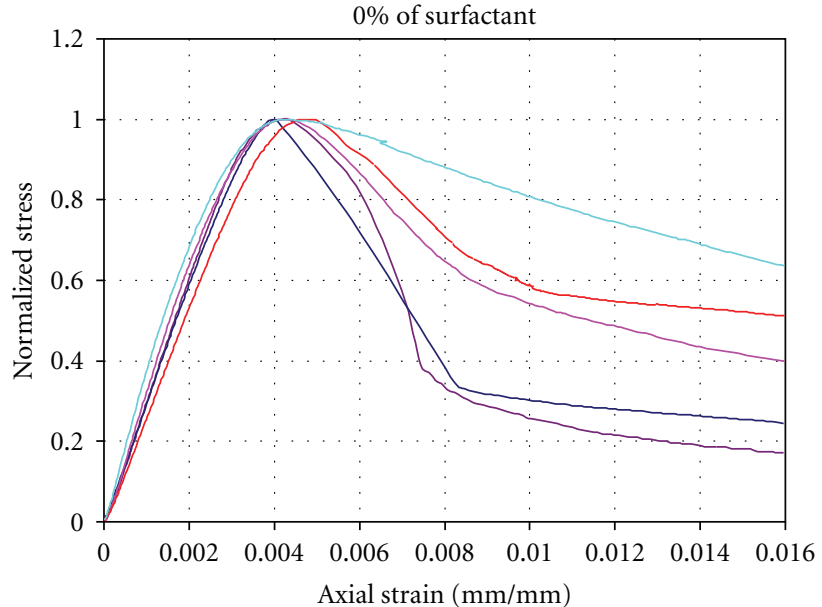

(a)

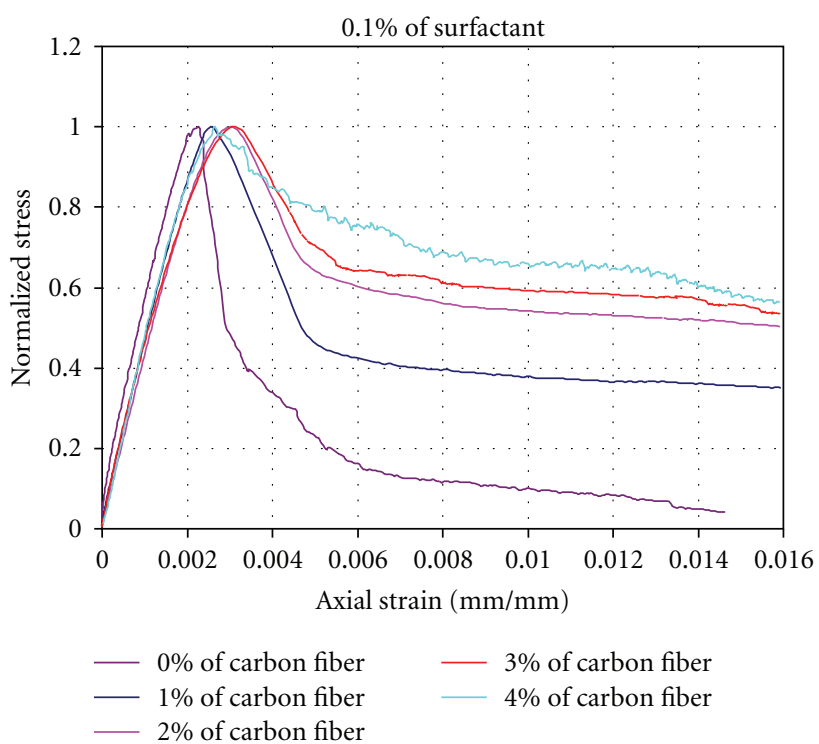

(c)

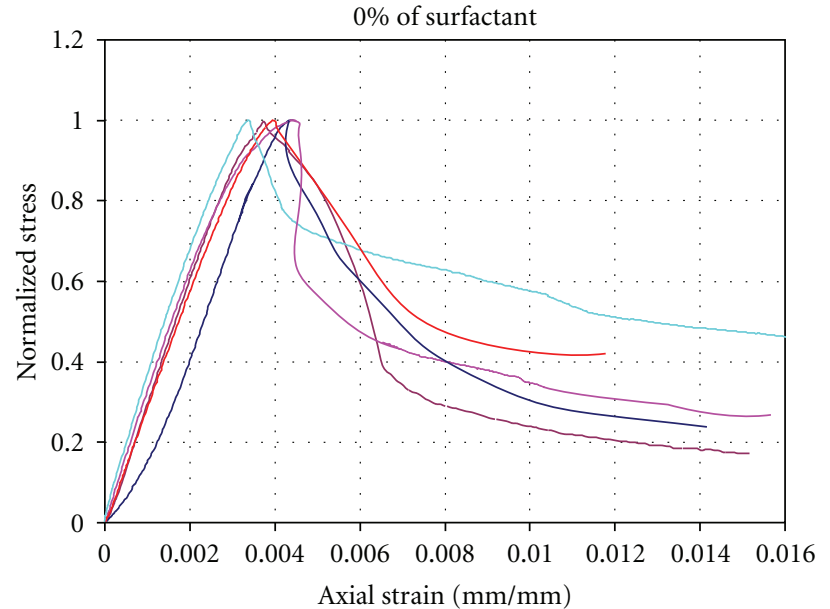

(b)

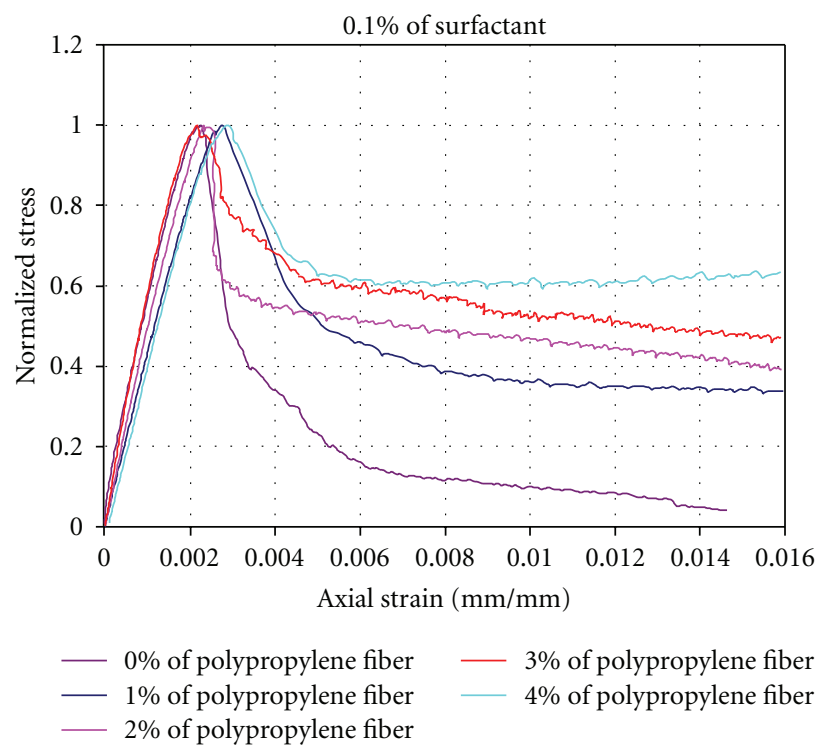

(d)

FIGURE 5: Normalized stress-strain curves for carbon and polypropylene fiber.

where $\mathrm{TI}=$ toughness index, $\varepsilon_{i}=$ strain at inflection point, and $\varepsilon_{0}=$ strain at maximum stress.

\section{Proposed Stress-Strain Constitutive Model}

The stress-strain behavior of the material in compression is needed to design structures using FALC. The shape of the uniaxial stress-strain curve is strongly affected by the following two conditions: one for testing, the other for concrete characteristics. Testing condition includes stiffness of the testing machine, size and shape of the specimen, specimen versus machine stiffness, strain rate, and type of loading. The other is W/C ratio, cement characteristics, unit weight, and aggregate characteristics. While the compressive strength is used for strength calculations of the structural components for FALC, the descending portion of the stress-strain curve is needed to evaluate the toughness resistance that is important for the ductility of structures.

In this study, the mathematical equation is based on compressive strength, unit weight, fiber volume fraction, fiber aspect ratio, and modulus of elasticity of fibers. The equation should be a simple form to apply for designing structures. The ascending portion of the curve must include not only the modulus of elasticity with unit weight and compressive strength, but also the compressive strength with fiber volume fraction. Descending portion after the infection point includes toughness index with reinforcing index.

A best-curve fitting with a second-order polynomials equation by statistical analysis was performed to obtain a relationship between the parameters $a, b$ up to the inflection point in the descending portion of stress-strain curve and $\gamma$ from inflection point to end. 


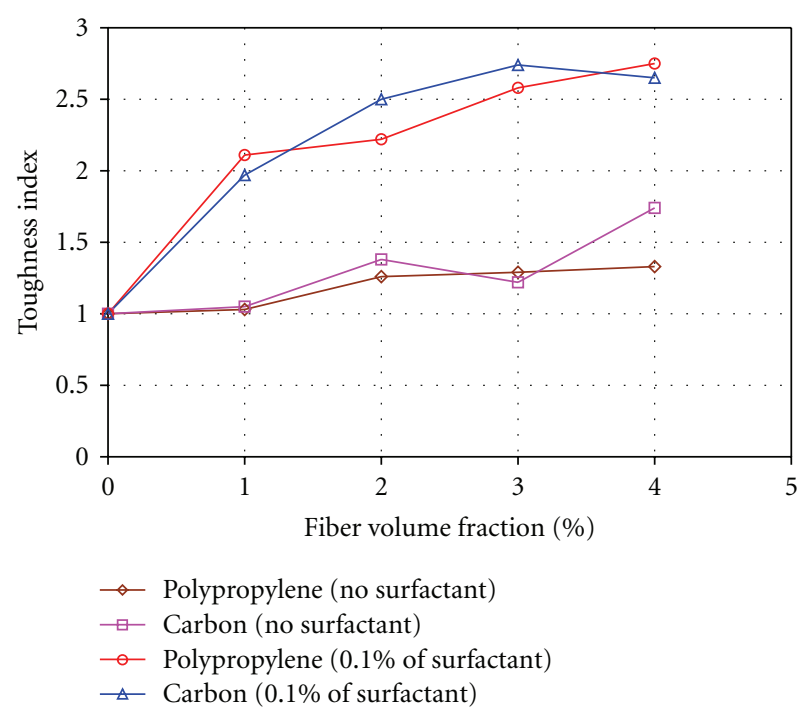

Figure 6: Toughness index versus fiber volume fraction.

4.1. Ascending Portion of Stress-Strain Curve. A mathematical equation of the following form describes the ascending portion of fiber aerated lightweight concrete's stress-strain curve:

$$
\frac{f_{c}^{\prime}}{f_{c f}^{\prime}}=\frac{\left(\varepsilon / \varepsilon_{0}\right)}{\left[1-\left(\varepsilon / \varepsilon_{0}\right)+a\left(\varepsilon / \varepsilon_{0}\right)^{b}\right]}, \quad 0 \leq \varepsilon \leq \varepsilon_{i},
$$

where $f_{c}^{\prime}=$ compressive stress; $f_{c f}^{\prime}=$ maximum compressive stress; $\varepsilon=$ strain; $\varepsilon_{0}=$ strain at maximum stress; $a, b=$ parameters to be calculated; $\varepsilon_{i}=$ strain at inflection point.

The parameter " $a$ " controls the compressive strength of the curve at the peak point. To find the parameter " $a$ ", since one raised to any power is one; $\left(\varepsilon / \varepsilon_{0}\right)=1$ at the peak point,

$$
\frac{f_{c}^{\prime}}{f_{c f}^{\prime}}=\frac{1}{a(1)^{b}}, \quad f_{c}^{\prime}=\frac{f_{c f}^{\prime}}{a} .
$$

As indicated, the compressive strength of the concrete had a good correlation with fiber volume fraction. The following equations were developed:

$$
\begin{aligned}
& a=1.052+0.16652 \cdot V_{f} \text {-for polypropylene fiber, } \\
& a=1.066+0.1595 \cdot V_{f} \text {-for carbon fiber. }
\end{aligned}
$$

The parameter " $b$ ", related to the slope of the descending portion of the stress-strain curve, is proposed in the analytical model. The " $b$ " value is dependent on the modulus of elasticity $\left(E_{f}\right)$ and aspect ratio $(l / \phi)$ of the fiber. For a FALC, the slope of the descending portion increases with the modulus of elasticity and aspect ratio of fiber.

4.2. Descending Portion of Stress-Strain Curve. An increase in the volume fraction and modulus of elasticity of fibers generally led to an increase in the slope of the descending portion of the stress-strain curve. For the case of both fibers,

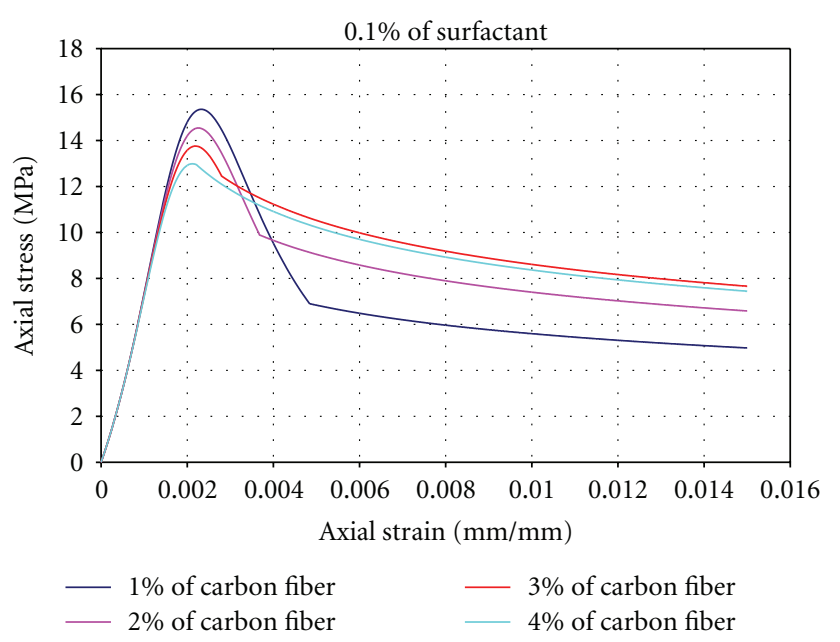

(a)

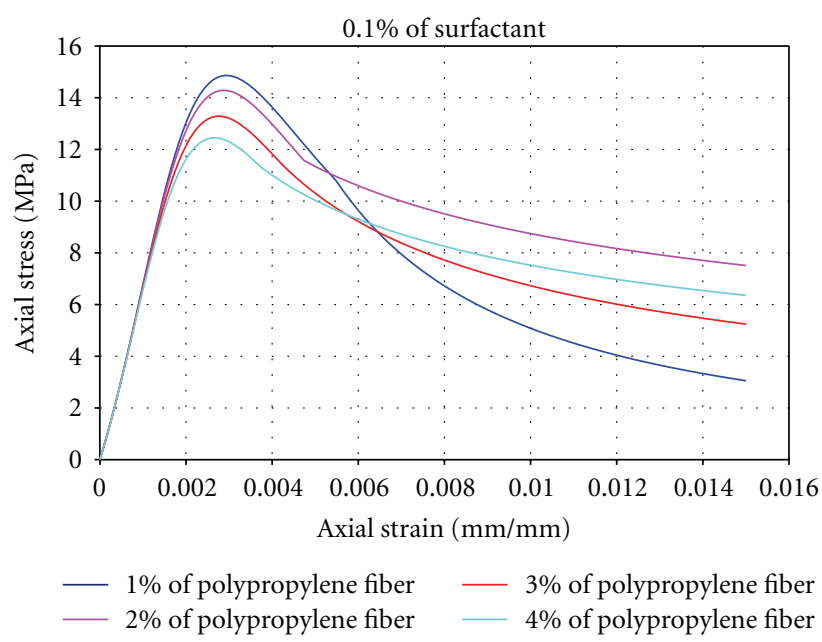

(b)

Figure 7: Proposed stress-strain curves of fiber aerated lightweight concrete.

an increase in fiber volume fraction at a constant volume fraction led to similar results. The aspect ratio and the fiber length seem to play an important role in improving the peak strain and the toughness of the composite. Everything else being equal, improvements due to fiber addition were relatively more significant at lower matrix compressive strengths.

The aggregates in FALC have lower stiffness than the mortar matrix as opposed to normal concrete. Thus, compressive loads are mainly carried by the stiffer mortar matrix corresponding to the stiffness relation between matrix and aggregates, which causes transverse tensile stresses in the aggregates and matrix. Finally, failure occurs after exceeding the tensile capacity of the aggregates. The cracks usually propagate straight through the aggregate particles. The smooth fracture surfaces transfer less stress and initiate a brittle failure.

A simple mathematical equation of the following form describes the ascending portion of fiber aerated lightweight 
concrete's stress-strain curve. To prevent a discontinuity in the descending portion of the curve, $f_{c i}^{\prime}$ was chosen instead of $f_{c}^{\prime}$ :

$$
f_{c}^{\prime}=f_{c i}^{\prime}\left(e^{-\gamma / \varepsilon}\right) \quad \varepsilon_{i}<\varepsilon
$$

where $f_{c i}^{\prime}=$ fiber concrete strength at inflection point, $\varepsilon=$ strain, and $\gamma=$ a parameter to be calculated, the parameter " $\gamma$ " depends on the reinforcing index (RI).

Figure 7 shows the analytical axial stress versus axial strain with polypropylene fiber and carbon fiber. To demonstrate the effectiveness of types of fibers, the axial stress versus axial strain relations predicted by the fixed surfactant was computed and compared with the different fiber volume fraction.

\section{Conclusions}

The experimental work reported here sought to characterize the mechanical properties and stress-strain behavior of fiber aerated lightweight concrete. The following conclusions were drawn.

(1) Using conventional lightweight aggregate, FALC air dry densities as low as $1137 \mathrm{~kg} / \mathrm{m}^{3}$ can be achieved by adding $0.1 \%$ of surfactant and additives.

(2) Both compressive strength and elastic modulus are strongly dependent on the amount of air in the concrete. The increase in surfactant content results in a less compressive strength and elastic modulus compared to nonsurfactant concrete.

(3) Both the compressive strength and elastic modulus are weakly dependent on the amount of fiber in the concrete.

(4) The toughness index is strongly dependent on the amount of fiber in the aerated concrete. While an increased polypropylene fiber volume fraction improves the toughness index of the concrete, carbon fiber improves this index to a greater degree.

(5) The stress-strain curve was represented by using a fractional equation based on the reinforcing index. A fair correlation was achieved in predicting the stressstrain curve.

\section{References}

[1] ACI Committee 318, Building Code Requirements for Reinforced Concrete (ACI 318-05) and Commentary, American Concrete Institute, Detroit, Mich, USA, 2005.

[2] Building Research Establishment, "Autoclaved aerated concrete," Building Research Establishment Digest 342, pp. 1-8, March 1989.

[3] F. C. Mc Cormick, "Rational proportioning of preformed foam cellular concrete," ACI Journal, vol. 64, pp. 104-110, 1967.

[4] A. S. Ezeldin and P. N. Balaguru, "Normal- and high-strength fiber-reinforced concrete under compression," Journal of Materials in Civil Engineering, vol. 4, no. 4, pp. 415-429, 1992.

[5] C. H. Henager, "Steel fibrous concrete-a review of testing procedures," in Proceedings of the Symposium on Fiber Concrete, pp. 16-28, London, UK, 1980.
[6] C. D. Johnston, Fiber Reinforced Cements and Concretes, Gordon and Breach Science, Amsterdam, The Netherlands, 2001.

[7] R. N. Swamy, P. S. Mangat, and C. V. S. K. Rao, The Mechanics of Fiber Reinforcement of Cement Matrices, Fiber Reinforced Concrete, SP 44, American Concrete Institute, Detroit, Mich, USA, 1973. 

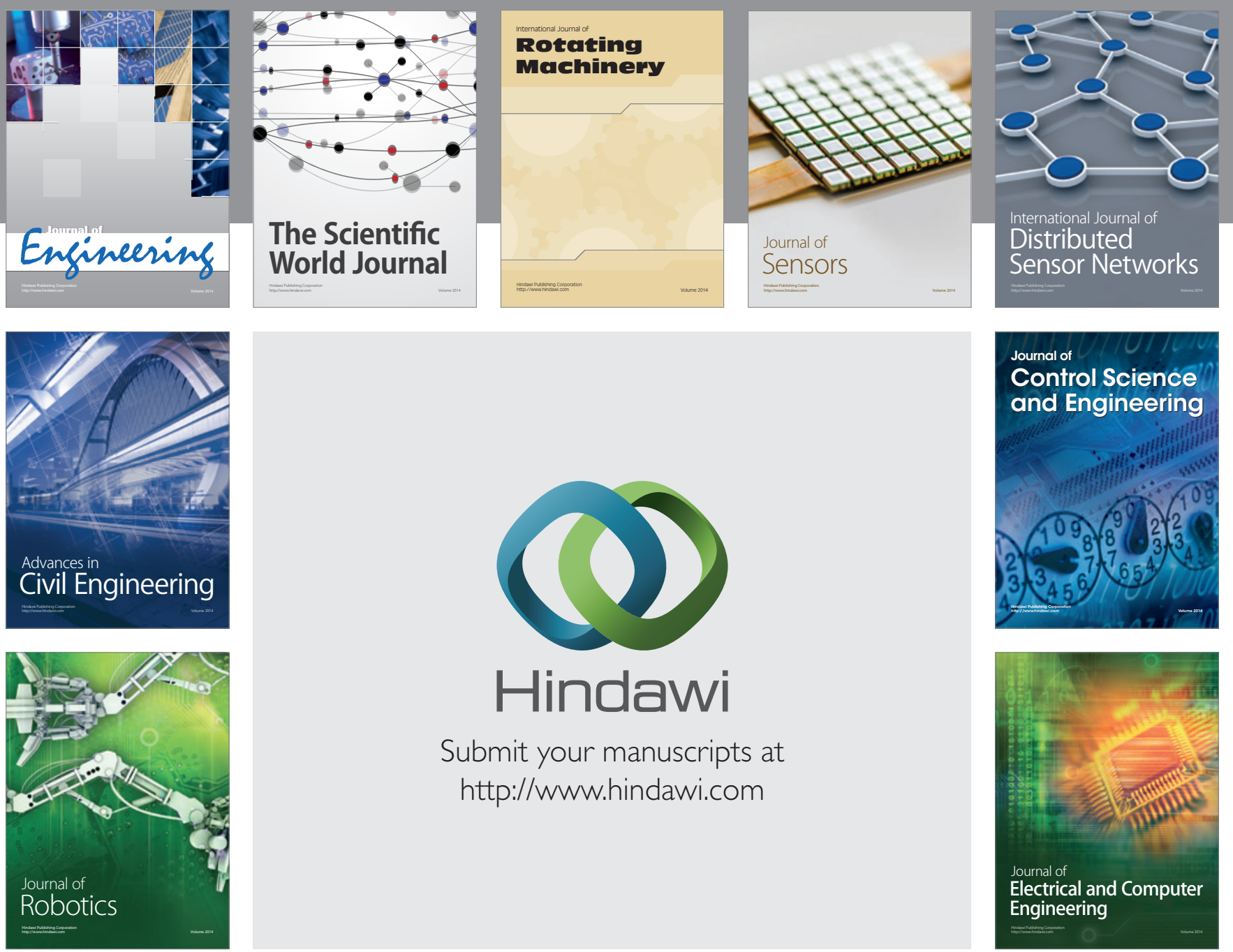

Submit your manuscripts at

http://www.hindawi.com
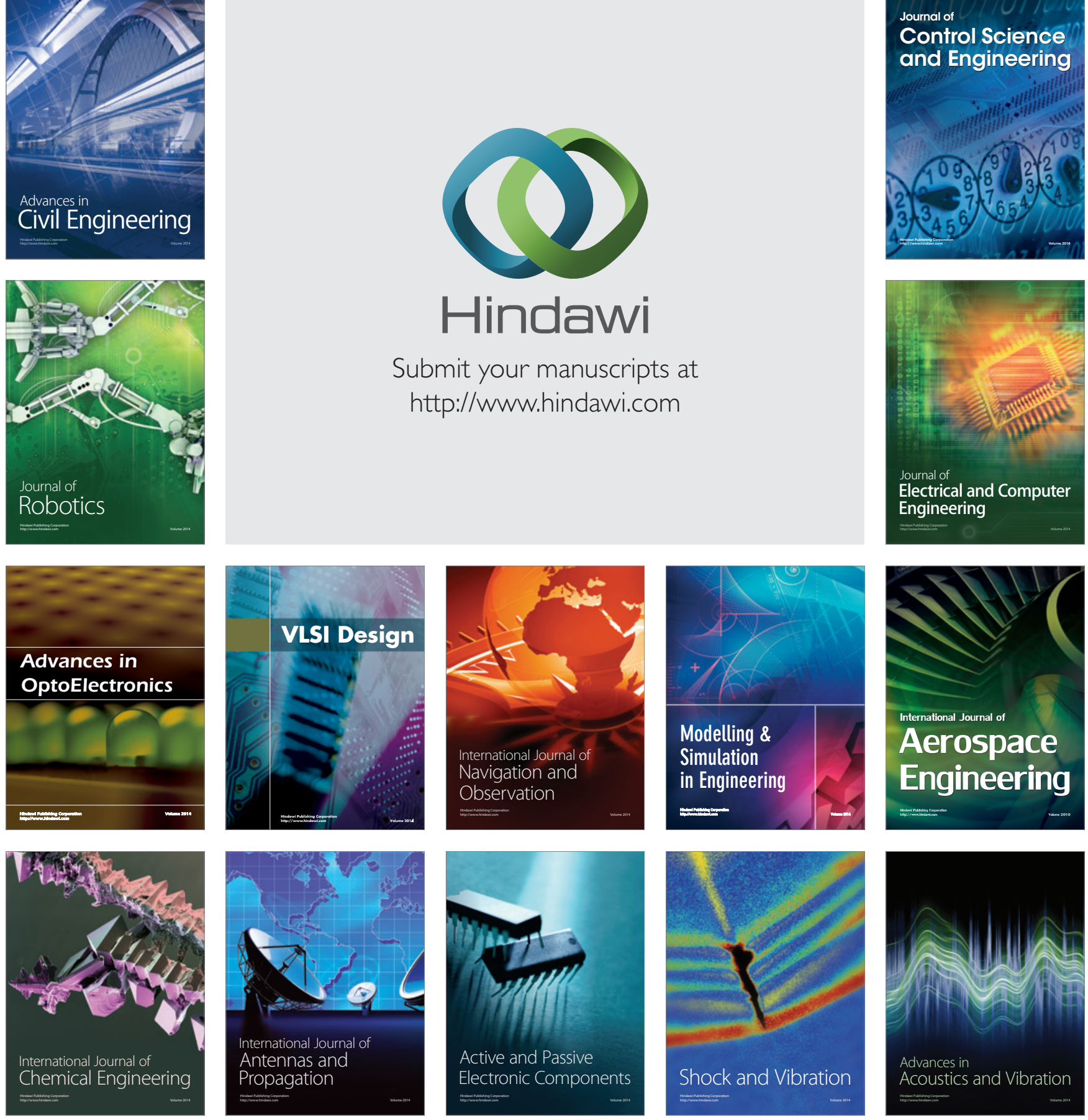